\title{
Concurrent Exposure to Methamphetamine and Sexual Behavior Enhances Subsequent Drug Reward and Causes Compulsive Sexual Behavior in Male Rats
}

\author{
Karla S. Frohmader, ${ }^{1,2}$ Michael N. Lehman, ${ }^{1,2}$ Steven R. Laviolette, ${ }^{1}$ and Lique M. Coolen ${ }^{1,2,3}$ \\ ${ }^{1}$ Department of Anatomy and Cell Biology, Schulich School of Medicine and Dentistry, University of Western Ontario, London, Ontario N6A 5C1, Canada, \\ and ${ }^{2}$ Department of Molecular and Integrative Physiology and ${ }^{3}$ Department of Psychology, University Michigan, Ann Arbor, Michigan 48109
}

\begin{abstract}
Methamphetamine (Meth) users report having heightened sexual pleasure, numerous sexual partners, and engaging in unprotected sex due to loss of inhibitory control. This compulsive sexual behavior contributes to increased prevalence of sexually transmitted infections, but the neural basis for this is unknown. We previously established a paradigm for compulsive sexual behavior in male rats in which visceral illness induced by lithium chloride was paired with sexual behavior (Davis et al., 2010; Frohmader et al., 2010a). The current study examined the effects of repeated Meth administration on sexual performance, compulsive sexual behavior, and sex or Meth reward. First, results demonstrated that seven daily administrations of $2 \mathrm{mg} / \mathrm{kg}$, but not $1 \mathrm{mg} / \mathrm{kg}$, Meth increased latencies to initiate mating. This impairment was evident $30 \mathrm{~min}$ after last Meth administration, but dissipated after 1 or $7 \mathrm{~d}$ of subsequent drug abstinence. Repeated 1 $\mathrm{mg} / \mathrm{kg}$ Meth exposure resulted in compulsive sex-seeking behavior 2 weeks following last Meth administration. This effect was dependent on Meth administration being concurrent with sexual experience and was not observed in sexually experienced animals that received Meth alone. Moreover, concurrent Meth and sexual experience enhanced conditioned place preference (CPP) for Meth, and for concurrent Meth and mating compared with Meth or mating alone. In contrast, CPP for mating alone was decreased. Together, these data indicate that the association between drug use and mating may be required for expression of compulsive sexual behavior and is correlated with increased reward seeking for concurrent Meth exposure and mating.
\end{abstract}

\section{Introduction}

Sexual health-related diseases within addict populations have raised awareness of the effects of drugs of abuse on sexual behavior, as chronic drug use is associated with unsafe sexual practices resulting in increased prevalence of sexually transmitted infections, including human immunodeficiency virus (HIV) (Crowe and George, 1989; Peugh and Belenko, 2001; Sánchez et al., 2002; Raj et al., 2007; Fisher et al., 2011). These effects of drugs on sexual behavior are well documented for the psychostimulant methamphetamine (Meth). Meth users often report heightened sexual desire, arousal, and pleasure and identify these factors as primary motivation for drug use (Semple et al., 2002; Schilder et al., 2005; Green and Halkitis, 2006). Moreover, Meth abuse is commonly associated with loss of inhibitory control of sex behavior or sexually compulsive behavior (Halkitis et al., 2001; McKirnan et al., 2001; Rawson et al., 2002; Green and Halkitis, 2006) and increased

\footnotetext{
Received Aug. 4, 2011; revised Sept. 8, 2011; accepted Sept. 23, 2011.

Author contributions: K.S.F., M.N.L., S.R.L., and L.M.C. designed research; K.S.F. performed research; K.S.F. and L.M.C. analyzed data; K.S.F. and L.M.C. wrote the paper.

This work was supported by Canadian Institutes of Health Research Grant RN 014705 to L.M.C.

The authors declare no competing financial interests.

Correspondence should be addressed to Lique M. Coolen, University of Michigan, Department of Molecular and

Integrative Physiology, Medical Science II, Room 7732B, 1137 E. Catherine Street, Ann Arbor, MI 48109-5663.

E-mail: coolenIm@umich.edu.

DOI:10.1523/JNEUROSCI.4013-11.2011

Copyright $\odot 2011$ the authors $\quad 0270-6474 / 11 / 3116473-10 \$ 15.00 / 0$
}

prevalence of HIV (Frosch et al., 1996; Halkitis et al., 2001; Parsons and Halkitis, 2002).

Human reports demonstrating Meth use as a predictor of sexual risk behaviors are based on self-reports from chronic Meth users that lack a reliable measurement for the relationship between Meth use and sexual behavior (Frohmader et al., 2010b). Thus, an investigation into Meth-induced changes in sexual behavior under controlled experimental settings using an animal model is required to understand the complex association between Meth and sexual behavior.

Recently, our laboratory examined the effects of acute Meth on compulsive sex-seeking in male rats (Frohmader et al., 2010a). These studies used a conditioned sex aversion paradigm in which male rats learned to associate mating with subsequent visceral illness (Peters, 1983; Agmo, 2002). Once this association between mating and the aversive stimulus was established, animals would not initiate mating behavior (Davis et al., 2010; Frohmader et al., 2010a). Meth pretreatment of a single injection weeks before conditioning disrupted the acquisition of inhibited sexual responses (Frohmader et al., 2010a). Thus, Meth-pretreated male rats were seeking sexual behavior even though mating was associated with an aversive stimulus; this was termed maladaptive or compulsive mating.

As previous studies testing the effects of an acute drug injection and research investigating the effects of repeated Meth on male rat sexual behavior is limited, the main goal of the current study was to investigate the effects of repeated Meth administra- 
tion on different aspects of sexual behavior including performance, compulsive seeking of sex, and reward. First, the effects of repeated Meth on mating were tested following drug administration and after periods of drug abstinence to distinguish between short- and long-term effects of Meth on sexual function. Next, the effects of repeated Meth administration on maladaptive sex behavior were investigated, implementing the conditioned sex aversion paradigm. In addition, it was determined whether learned associations between repeated Meth exposure and sexual behavior were essential for the effects of Meth on maladaptive sexual behavior. Finally, it was tested whether repeated Meth exposure results in enhanced reward for Meth and/or mating, as determined by conditioned place preference (CPP) paradigms.

\section{Materials and Methods Subjects}

Adult male Sprague Dawley rats (210-225 g) were obtained from Charles River Laboratories and housed in same-sex pairs in standard Plexiglas cages (home cages) containing pieces of PVC pipe for environmental enrichment. Animals were housed in a room maintained at a 12/12 h reversed light/dark cycle (lights off at 11:00 A.M.) with food and water available ad libitum. All testing was performed during the dark cycle under red illumination. Stimulus females (200-225 g; Charles River Laboratories) used for sexual behavior were bilaterally ovariectomized and received a subcutaneous implant containing $5 \%$ estradiol benzoate and $95 \%$ cholesterol. To induce sexual receptivity, females were administered $0.5 \mathrm{mg}$ of progesterone in $0.1 \mathrm{ml}$ of sesame oil (s.c.) 4 h before sexual behavior. Experimental procedures were approved by the Animal Care Committee at the University of Western Ontario and the University of Michigan Committee on Animal Care and Use and were in agreement with guidelines outlined by the Canadian Council on Animal Care and National Institutes of Health.

\section{Experimental designs \\ Sexual behavior}

The current experiment investigated the effects of repeated Meth on sexual performance and motivation immediately following drug injection and following drug abstinence periods. Thirty-three male rats gained sexual experience in separate test cages (mating arenas; $60 \times 45 \times$ $50 \mathrm{~cm}$ ) containing clean bedding during five twice-weekly mating sessions. During each mating session, males were allowed to mate with a receptive female until the display of one ejaculation or for $1 \mathrm{~h}$, whichever occurred first. One week following the last mating session, males were habituated to experimental procedures and received a subcutaneous injection of $1 \mathrm{ml} / \mathrm{kg}$ saline for three consecutive days. Following each injection, animals were placed in Plexiglas locomotor activity chambers $(40.5 \times 40.5 \mathrm{~cm}$; Med Associates $)$ equipped with $16 \times 16$ photobeam arrays; locomotor activity was recorded for $30 \mathrm{~min}$. In addition to recording ambulatory behavior following treatment injection, placing males in the locomotor chambers provided a drug-associated environment distinct from that of mating behavior. Next, males received a daily injection of 1 or $2 \mathrm{mg} / \mathrm{ml} / \mathrm{kg}$ Meth or vehicle (saline, $1 \mathrm{ml} / \mathrm{kg} ; n=11$ each) for 7 consecutive days. Following each injection, males were placed in the locomotor activity chambers and locomotor activity was recorded for 30 min, after which they returned to their holding cages. On the last day of Meth administration, males were removed from the locomotor activity chamber after $30 \mathrm{~min}$ and placed in the mating arena to test for effects of Meth on sexual behavior. Animals were tested again for sexual behavior in the mating arenas following $1 \mathrm{~d}$ or 1 week of drug abstinence.

During the mating sessions, standard parameters for sexual behavior were observed and recorded, including latencies to mount (time from introduction of female to first mount) and intromission (time from introduction of female to first intromission), which are indicative of sexual motivation (Hull et al., 2002), as well as latency to ejaculation (time from first intromission to ejaculation), numbers of mounts and intromissions before ejaculation, and postejaculatory interval, which are measures of sexual performance (Hull et al., 2002; Pfaus, 2009). Differences between groups were determined for each parameter of sexual behavior using nonparametric Kruskal-Wallis analysis and Dunn's post hoc comparisons, at significance levels of 0.05 .

\section{Locomotor activity}

Locomotor activity following each Meth injection was analyzed using Med Associates analysis software as distance traveled within 5 min intervals. Group differences were examined using nonparametric Kruskal-Wallis analysis and Dunn's post hoc comparisons. To examine Meth-induced locomotor sensitization, Meth-induced activity during the last $10 \mathrm{~min}$ of the test was compared between the first and seventh injection day within each drug dose treatment group using paired $t$ tests. A significance level of 0.05 was applied to all comparisons.

\section{Conditioned sex aversion}

Experiment 1. First, 50 male rats were habituated to saline injections for three consecutive days and males gained sexual experience during three mating sessions. Before each mating session, animals were injected with either $1 \mathrm{mg} / \mathrm{kg}$ Meth or $1 \mathrm{ml} / \mathrm{kg}$ saline (s.c.), placed in mating arenas, and, $30 \mathrm{~min}$ later, were allowed to mate with a receptive female until ejaculation or $1 \mathrm{~h}$. Parameters for sexual behavior were recorded and analyzed (see Sexual behavior, above). Two weeks later, animals were subjected to a conditioned sex aversion paradigm. Males were subdivided into four experimental groups according to pretreatment (Meth or saline) and conditioning [lithium chloride ( $\mathrm{LiCl}$ )-paired or -unpaired]; groups were saline-unpaired $(n=12)$, Meth-unpaired $(n=12)$, saline-paired $(n=$ $13)$, and Meth-paired $(n=13)$. The conditioned aversion paradigm consisted of eight consecutive $2 \mathrm{~d}$ conditioning trials. During the first day, all males were placed in the mating arena for a $10 \mathrm{~min}$ habituation period, after which a receptive female was introduced. Females were scented by swabbing almond oil on the neck and base of the tail before mating, as olfactory cues have been shown to facilitate male approach behavior and to strengthen conditioning (Lawrence and Kiefer, 1987; Agmo, 2002). Males were allowed to mate for $30 \mathrm{~min}$ or until one ejaculation. If intromissions did not occur within the first $15 \mathrm{~min}$, mating was terminated. One minute following ejaculation or trial termination, males were given a $127.2 \mathrm{mg} / \mathrm{kg}$ intraperitoneal injection of $10 \mathrm{ml} / \mathrm{kg} \mathrm{LiCl}$ (paired males) or saline (unpaired males). LiCl or saline were administered regardless of whether mating occurred. The following day, unpaired males received a $10 \mathrm{ml} / \mathrm{kg}$ injection of $\mathrm{LiCl}$ while paired males received saline. Animals were returned to the home cage after injections.

Experiment 2. To test whether the effects of Meth pretreatment on conditioned sex aversion were dependent on the simultaneous exposure to Meth and mating or due to Meth alone, an additional experiment was conducted. Male rats $(n=20)$ received sexual experience during five mating sessions but without Meth or saline treatments ( $n=10$ each). Instead, 1 week after sexual experience, they received seven once-daily injections of either Meth $(1 \mathrm{mg} / \mathrm{kg}$, s.c.) or saline and 2 weeks later were subjected to the conditioned sex aversion paradigm (see Experiment 1, above).

For both experiments and during each conditioning trial, parameters for sexual behavior were analyzed and group differences were determined for each conditioning trial using a two-way ANOVA (factors: Meth/saline pretreatment, conditioning). Pearson $\chi^{2}$ analysis was used to compare differences between groups in the percentages of males that displayed mounts, intromissions, or ejaculation within each conditioning trail.

\section{Conditioned place preference}

To test whether Meth pretreatment affected reward for Meth or sexual behavior, CPP experiments were conducted. A three-compartment apparatus (Med Associates) containing two larger outer chambers $(28 \times$ $22 \times 21 \mathrm{~cm}$ ) with distinguishable visual and tactile cues and separated by a small central compartment $(13 \times 12 \times 21 \mathrm{~cm})$, was used for all CPP experiments. Doors on both sides of the central compartment separated the chambers, and could be raised to allow the animals' free movement throughout the apparatus, or lowered to confine them to a particular area. The apparatus was equipped with photobeams to measure the time spent in each chamber. On the first day, a 15 min pretest was conducted to determine each animal's initial chamber preference, whereby each 
animal was allowed to roam freely between chambers of the CPP apparatus. No significant preferences for either chamber were detected between experimental groups. Animals were excluded from the study if they displayed an extended preference for a specific chamber (a difference over $120 \mathrm{~s}$; shown by $<10 \%$ of the subjects). Conditioning was conducted during days 2 and 3 . During conditioning, the initially unpreferred chamber (paired chamber) was paired with a reward manipulation for $30 \mathrm{~min}$. The initially preferred chamber (unpaired chamber) was paired with a control manipulation. The order in which the animals were exposed to the paired and unpaired chambers was counterbalanced within each experimental group. A posttest that was procedurally identical to the pretest was conducted on the fourth and final day.

Experiment 1. First, 50 male rats were habituated to saline injections for three consecutive days and males gained sexual experience during three mating sessions. During each mating session, animals were injected with either $1 \mathrm{mg} / \mathrm{kg}$ Meth or $1 \mathrm{ml} / \mathrm{kg}$ saline (s.c.), placed in test cages, and, $30 \mathrm{~min}$ later, allowed to mate with a receptive female until ejaculation or $1 \mathrm{~h}$. Parameters for sexual behavior were recorded and analyzed (for description, see Sexual behavior, above). One week later, animals were distributed into four experimental groups matched for drug treatment and sexual performance for CPP testing. During conditioning, males were injected with either Meth or saline (matching the prior drug treatment) and $30 \mathrm{~min}$ later were allowed to mate until ejaculation. One minute following ejaculation, the animal was placed into the paired chamber. The unpaired chamber was associated with either an injection (Meth or saline) or mating without an injection. Following the posttest, a preference score (the percentage of time spent in the paired chamber during the pretest and posttest; calculated as time spent on paired chamber divided by time in paired + unpaired chamber $\times 100$ ) and CPP score (Experiment 1; difference in time spent in the paired chamber during the posttest minus the pretest) were calculated for each subject. Preference scores were compared within experimental groups using paired $t$ tests and CPP scores were compared between experimental groups using a one-way ANOVA and Fisher's least significant difference test for post hoc comparisons, all with $95 \%$ confidence levels.

Experiment 2. To test whether effects of Meth pretreatment on CPP for Meth or mating were dependent on the simultaneous exposure to Meth and mating or due to Meth alone, an additional experiment was conducted. Male rats received Meth $(1 \mathrm{mg} / \mathrm{kg})$ and mating simultaneously for 4 consecutive days $(n=10)$. Two control groups remained sexually naive and received either Meth or saline ( $n=10$ each). One week later, CPP for Meth was conducted. All males received an injection of Meth in the paired chamber and a saline injection was associated with the unpaired chamber. Preference scores were calculated and compared within experimental groups using paired $t$ tests with significance level of 0.05 .

Experiment 3. To test whether simultaneous exposure to Meth and mating is critical for altered sexual reward, a mating CPP study was conducted. Male rats received either Meth $(1 \mathrm{mg} / \mathrm{kg})$ or saline simultaneously with mating for four consecutive days ( $n=10$ each). One week later, CPP for sexual behavior was tested. All males were placed in the paired chamber following mating and no mating was associated with the unpaired chamber. Preference scores were calculated and compared within experimental groups using paired $t$ tests with significance level of 0.05 .

\section{Conditioned place aversion}

To test whether Meth exposure alters sensitivity to LiCl-induced illness, a conditioned place aversion (CPA) experiment was conducted. CPA testing was conducted during the first half of the dark period using the same apparatus as that used for CPP experiments (see Conditioned place preference, above). For three consecutive days, male rats gained sexual experience concurrently with Meth $(1 \mathrm{mg} / \mathrm{kg})$ or saline $(n=10$ each). One week later, all males received an $\mathrm{LiCl}$ injection $(10 \mathrm{ml} / \mathrm{kg}$, i.p.) paired with the initially preferred chamber, while an equivalent dose of saline was associated with the initially unpreferred chamber. Following the posttest, mean preference score (the percentage of time spent in the paired chamber during the pretest and posttest; calculated as time spent on paired chamber divided by time in paired + unpaired chamber $\times 100)$ and CPA score (difference in time spent in the paired chamber during the posttest
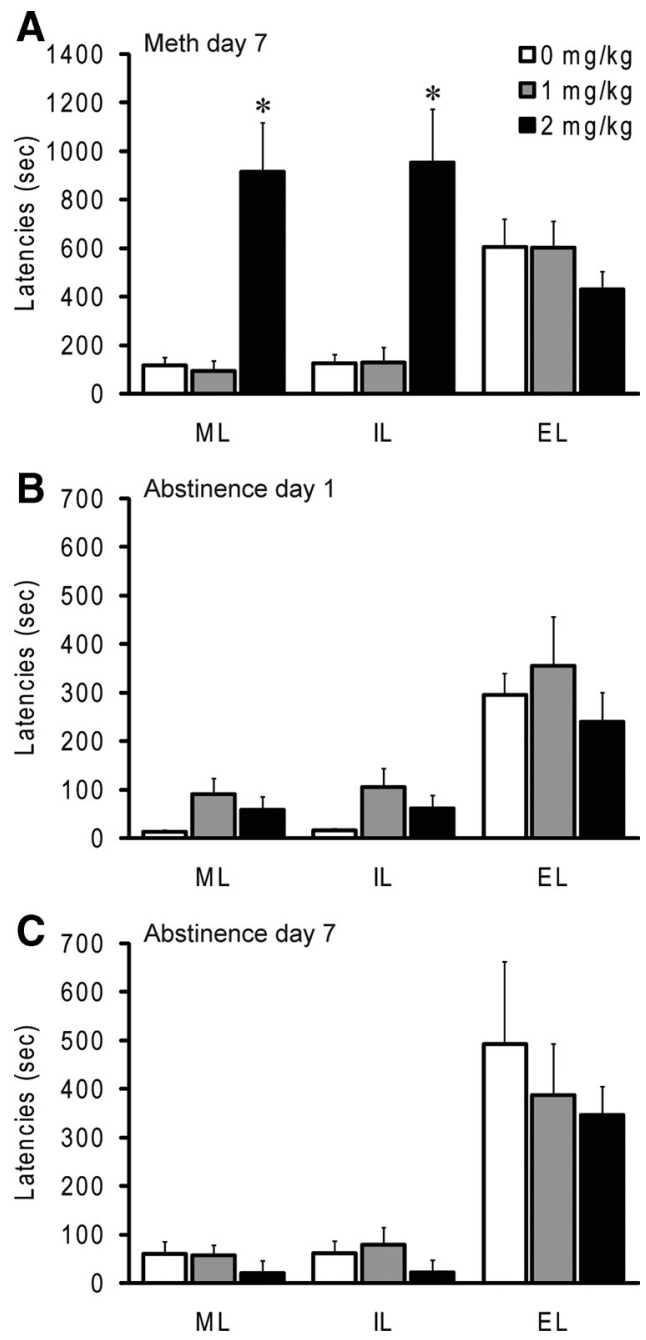

Figure 1. Effects of repeated Meth on sexual performance. $\boldsymbol{A}-\boldsymbol{C}$, Latencies to mount (ML), intromission (IL), and ejaculation (EL) following administration of 0 , 1, or $2 \mathrm{mg} / \mathrm{kg}$ Meth $30 \mathrm{~min}$ after the seventh and last drug injection $(\boldsymbol{A})$ and drug abstinence days $1(\boldsymbol{B})$ and 7 (C). Data are presented as mean \pm SEM. *Significant differences from saline-injected males $(p<0.05)$.

minus the pretest) were calculated for each subject. Preference scores were compared within experimental groups using paired $t$ tests, while CPA scores were compared between experimental groups using unpaired $t$ tests, all with significance level of 0.05 .

\section{Results}

\section{Sexual behavior}

Meth significantly affected initiation of sexual behavior when mating was tested $30 \mathrm{~min}$ following the last drug injection. This effect was dose-dependent at $2 \mathrm{mg} / \mathrm{kg}$, but not $1 \mathrm{mg} / \mathrm{kg}$, Meth. Meth significantly increased mount and intromission latencies ( $p=0.001$ and 0.002 , respectively) compared with saline controls (Fig. 1A). Meth did not affect the percentages of males that initiated behavior, and $100 \%$ of males mated in all three treatment groups. Meth did not have long-term effects on initiation of sexual behavior, as Meth-pretreated males did not display altered mating behavior compared with saline-pretreated controls when mating was tested during drug abstinence days 1 and 7 (Fig. $1 B, C)$. Finally, Meth did not affect sexual performance at any time as there were no effects on latencies to ejaculation (Fig. 1) or numbers of mounts and intromissions (data not shown). Thus, repeated Meth impaired initiation of mating when tested shortly 

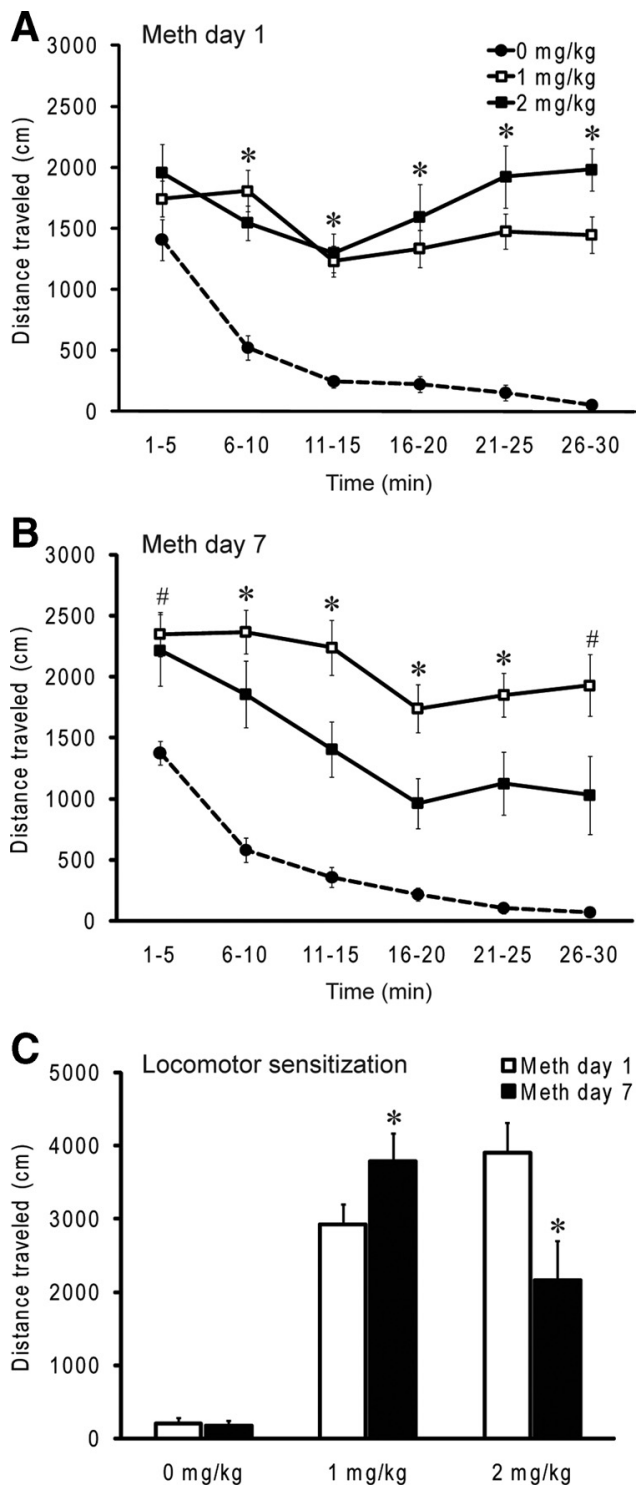

Figure 2. Effects of repeated Meth on locomotor activity. $\boldsymbol{A}, \boldsymbol{B}$, Distance traveled by males administered 0,1 , or $2 \mathrm{mg} / \mathrm{kg}$ Meth following the first $(\boldsymbol{A})$ and last $(\boldsymbol{B})$ Meth injection. Data are presented as mean \pm SEM. * Significant differences from control for all treatment groups $(p<$ $0.05)$; " significant differences between $1 \mathrm{mg} / \mathrm{kg}$ Meth and control only $(p<0.05)$. C, Methinduced sensitized locomotor response. Distance traveled by males administered 0,1 , or 2 $\mathrm{mg} / \mathrm{kg}$ Meth following the first and last Meth injection during the last $10 \mathrm{~min}$ of locomotor activity recordings. Data are presented as mean \pm SEM. * Significant difference from sexually naive males of the same treatment group $(p<0.05)$.

after administration, but did not have long-term effects on sexual motivation or performance.

\section{Locomotor activity}

Meth at either 1 or $2 \mathrm{mg} / \mathrm{kg}$ doses increased locomotor activity compared with controls ( $p<0.001,1$ and $2 \mathrm{mg} / \mathrm{kg}$; Fig. $2 A, B$ ). Repeated Meth administration resulted in a sensitized locomotor response-males that were administered $1 \mathrm{mg} / \mathrm{kg}$ Meth displayed a significantly greater locomotor activity following the last drug injection compared with the first injection ( $p=0.042$; Fig. $2 C$ ). In contrast, $2 \mathrm{mg} / \mathrm{kg}$ Meth resulted in significantly decreased locomotor activity on the last day compared with the first day $(p=0.009$; Fig. $2 C$ ), which may be indicative of increases in stereotypic behaviors.
Table 1. Overview of sexual behavior

\begin{tabular}{llll}
\hline & \multicolumn{2}{c}{ Mating session } & $\begin{array}{l}\text { Conditioning trial } \\
\text { Pretreament }\end{array}$ \\
\cline { 2 - 3 } & 1 & 3 & 1 \\
\hline $\begin{array}{l}\text { Sex }+ \text { saline } \\
\text { ML }\end{array}$ & $121.8 \pm 23.3$ & $211.3 \pm 123.6$ & $56.2 \pm 26.4$ \\
IL & $132.8 \pm 22.7$ & $260.4 \pm 123.3$ & $89.3 \pm 32.4$ \\
Sex + Meth & $156.4 \pm 47.9$ & $320.3 \pm 162.4$ & $55.2 \pm 10.8$ \\
ML & $168.1 \pm 47.1$ & $322.8 \pm 161.9$ & $60.5 \pm 11.8$ \\
IL & & & \\
\hline
\end{tabular}

Overview of sexual behavior during mating sessions 1 and 3 ( 30 min following saline or Meth administration) and during the first day of the conditioned sex aversion paradigm (Experiment 1; 2 weeks following pretreatment of mating concurrent with saline or Meth). Latencies to mount (ML) and intromission (IL) are presented as mean $\pm S E M$.

\section{Conditioned sex aversion}

Sexual behavior

During the Meth pretreatment phase of Experiment 1, sexual behavior was unaffected by $1 \mathrm{mg} / \mathrm{kg}$ Meth treatment during each of the three subsequent sessions compared with saline-pretreated males (Table 1). These results confirm lack of effects of this dose of Meth on sexual behavior, even when administered in the same environment. Moreover, Meth pretreatment did not alter sexual behavior during the first day of the conditioning paradigm (before $\mathrm{LiCl}$ pairing; Table 1) or during any of the conditioning trials in the LiCl-unpaired groups. These results confirm that Meth did not have long term effects on sexual behavior.

\section{Compulsive sexual behavior}

Experiment 1. In contrast, repeated Meth treatment did enhance compulsive sex seeking. In control, saline-pretreated animals, conditioned sex aversion significantly inhibited sexual behavior. Specifically, decreased percentages of LiCl-paired males that mounted and intromitted compared with unpaired salinepretreated males were first evident on the sixth $(p=0.039)$ conditioning trial and persisted through conditioning trial 7 ( $p=$ 0.005 ; data not shown) and $8(p<0.001$; Fig. $3 B)$. A significant difference in the percentage of males that ejaculated was first evident on the fourth $(p=0.041)$ conditioning trial and persisted throughout conditioning ( $p<0.001$; Fig. $3 C$ ). However, Meth pretreatment did affect conditioned sex aversion, as Methpretreated males paired with $\mathrm{LiCl}$ did not reach significant inhibition of sexual behavior until the last conditioning trial compared with unpaired Meth-pretreated males. Specifically, the percentages of Meth-pretreated LiCl-paired males displaying intromissions and ejaculation were significantly decreased only during conditioning trial 8 ( $p=0.03$ and $p=0.011$, respectively). Thus, Meth pretreatment 2 weeks before the onset of conditioning resulted in maladaptive or compulsive sex-seeking behavior.

Experiment 2. The effects of Meth pretreatment on conditioned sex aversion were dependent on concurrent Meth and mating experience. Specifically, conditioned sex aversion was not affected in sexually experienced males that received Meth pretreatment and mating experience at different times (nonconcurrent). Percentages of Meth-pretreated LiCl-paired males that displayed mounts and ejaculations were not different from saline-pretreated paired males (Fig. 4). These data suggest that the initial association between Meth and sexual experience was a contributing factor to the effects of Meth on compulsive sex behavior.

\section{Conditioned place aversion}

Additional control experiments revealed that the inability to inhibit mating following Meth pretreatment is not due to a blunted sensitivity to LiCl-induced visceral illness, as all males formed an 
A
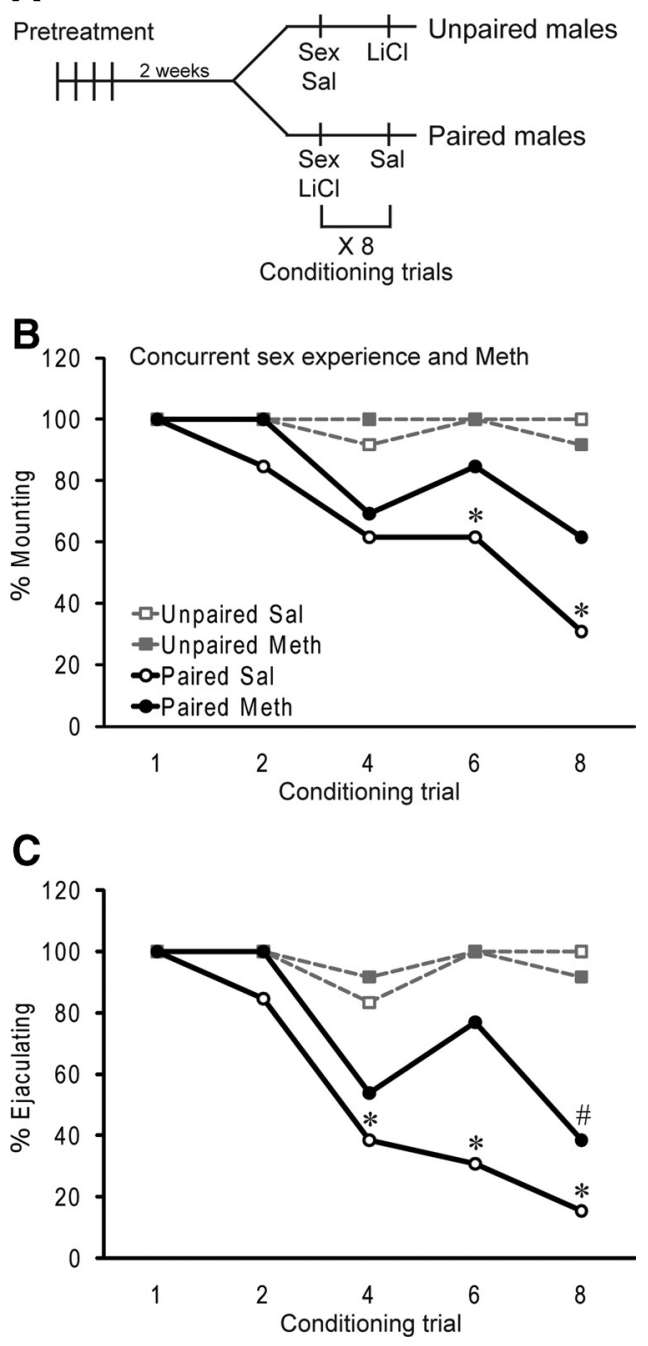

Figure 3. Effects of concurrent mating (sex) and Meth pretreatment on conditioned sex aversion (Experiment 1).A, Experimental groups included saline-(Sal) or Meth-pretreated males that received LiCl following mating (Paired males) and saline- or Meth-pretreated males that received saline following mating (Unpaired males). During the second day of each conditioning trial, paired males received saline and unpaired males received $\mathrm{LiCl} \boldsymbol{B}, \boldsymbol{C}$, Percentage of males mounting $(\boldsymbol{B})$ and ejaculating ( $C$ during conditioned sex aversion following Meth pretreatment administered simultaneously with sexual experience. *Significant difference from saline-pretreated unpaired males $(p<0.05)$; "significant difference from Meth-pretreated unpaired males $(p<0.05)$.

aversion to the chamber associated with a single dose of LiCl. Specifically, both saline- and Meth-pretreated males spent significantly less time in the LiCl-paired chamber during the posttest compared with the pretest $(p=0.037$ and 0.045 , respectively; Fig. $5 A$ ). Moreover, the difference of time spent in the LiCl-paired chamber following the posttest versus pretest was identical in Meth- and saline-pretreated groups (Fig. 5B).

\section{Conditioned place preference}

Experiment 1

Self-report studies reveal that Meth use enhances sexual pleasure and is a primary motivation for drug use (Semple et al., 2002; Schilder et al., 2005; Green and Halkitis, 2006). This Methinduced enhancement of sexual pleasure has not been tested in the rodent model. Therefore, CPP paradigm was used to test whether sexual behavior with Meth is more rewarding than either mating or Meth administration alone. In agreement with previ-
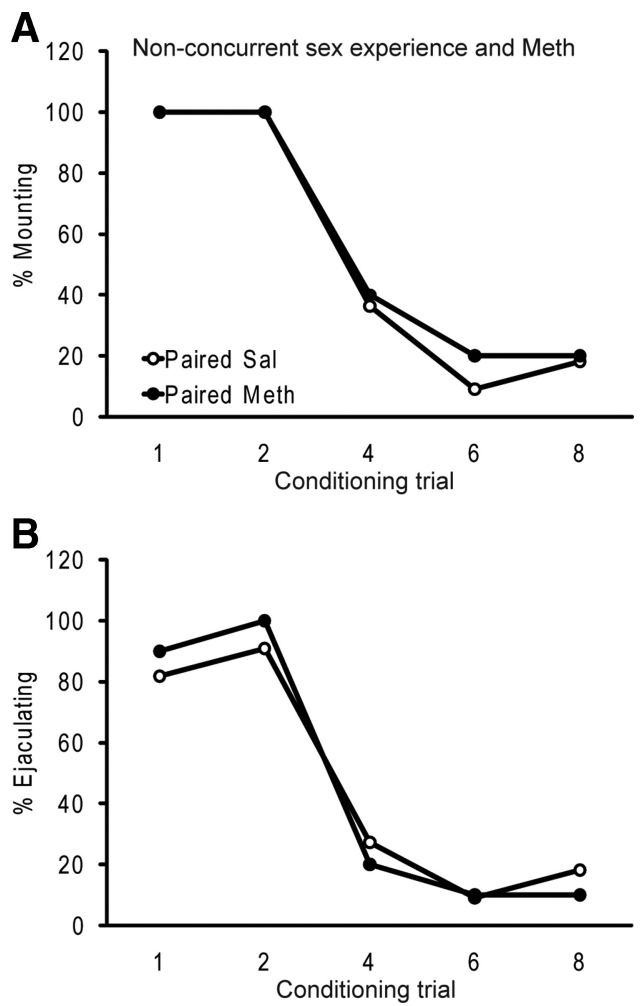

Figure 4. Effects of nonconcurrent mating (sex) and Meth pretreatment on conditioned sex aversion (Experiment 2). $\boldsymbol{A}, \boldsymbol{B}$, Percentage of males mounting $(\boldsymbol{A})$ and ejaculating $(\boldsymbol{B})$ during LiCl conditioned sex aversion following Meth pretreatment not associated with sexual experience. Two groups were included: LiCl-paired pretreated with saline and LiCl-paired pretreated with Meth.
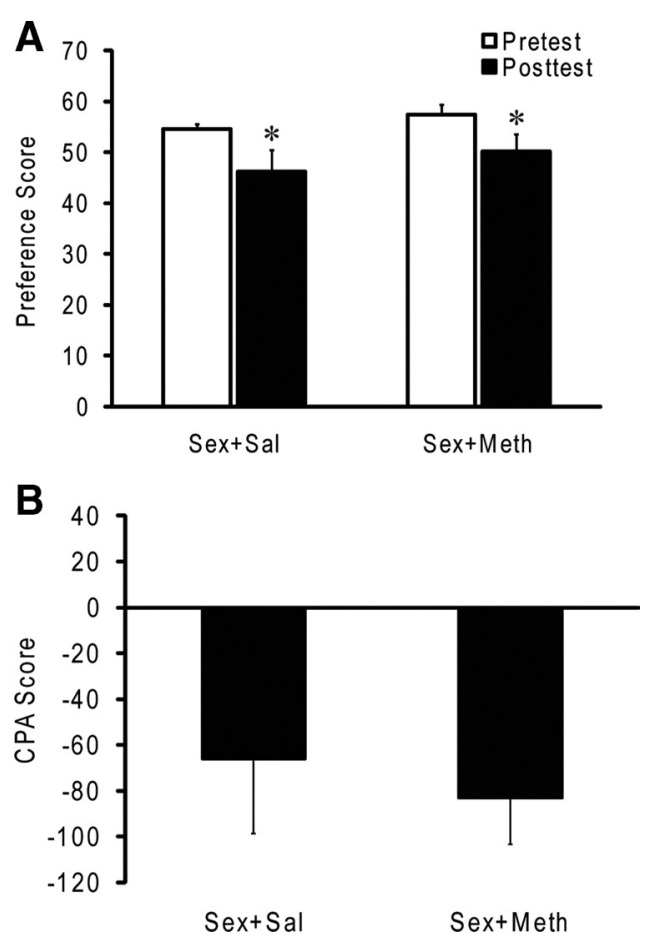

Figure 5. Effects of concurrent mating (sex) and Meth pretreatment on LiCl-induced CPA. $\boldsymbol{A}$, $\boldsymbol{B}$, Preference score (time spent on paired chamber divided by time in paired + unpaired chamber $\times 100 ; A$ ) and (PA score (difference in time spent in the paired chamber during the posttest minus pretest; $\boldsymbol{B}$ ) in mated males pretreated with saline (Sal; sex + saline) or Meth (sex + Meth). Data are presented as mean \pm SEM. * Significant differences from pretest within the same experimental group $(p<0.05)$. 
A

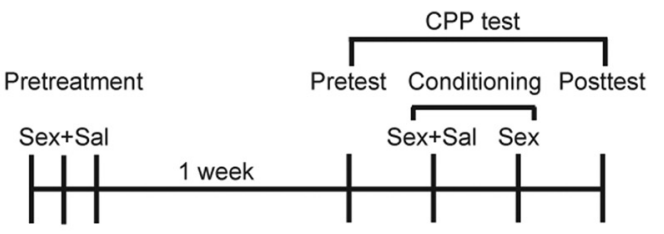

B

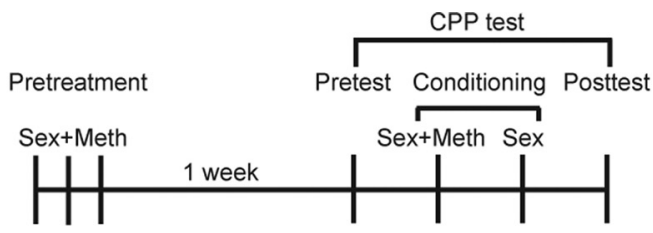

C

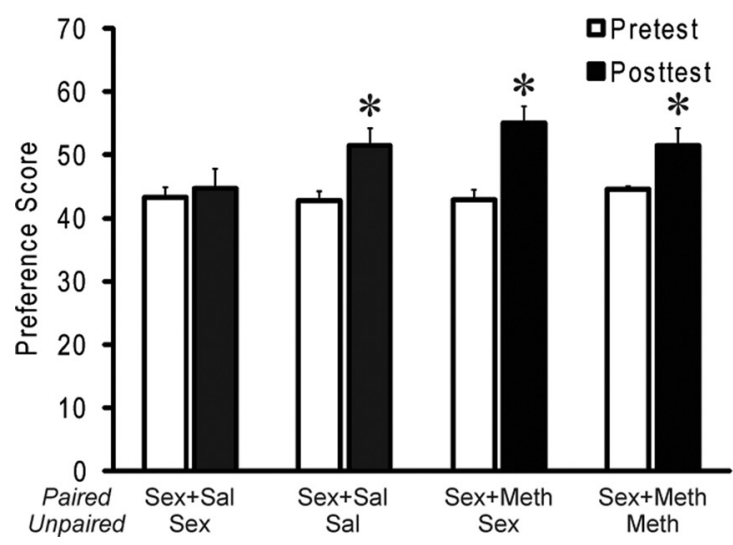

D

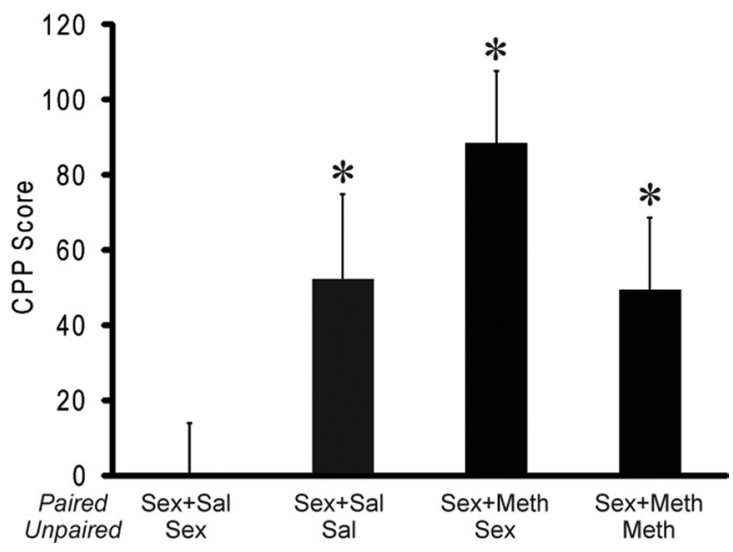

Figure 6. Effects of concurrent mating (sex) and Meth pretreatment on mating- and Meth-induced CPP (Experiment 1). Four groups were included. $A$, Two groups received sex + saline (Sal) pretreatment and the following treatment in the paired/unpaired chamber: sex + saline/sex, sex + saline/saline. The first group served as a negative control, as saline was not expected to alter CPP for sex. The second group served as a positive control, as sex was expected to cause CPP. $\boldsymbol{B}$, The other two groups received sex + Meth pretreatment and the following in the paired/unpaired chambers: sex + Meth/sex or sex + Meth/Meth. The order in which the animals were exposed to the paired and unpaired chambers was counterbalanced within each experimental group. C, Preference score (time spent on paired chamber divided by time in paired + unpaired chamber $\times 100$ ). Data are presented as mean \pm SEM. *Significant differences from pretest within the same experimental group $(p<0.05)$. D, CPP score (difference in time spent in the paired chamber during the posttest minus the pretest). Data are presented as mean \pm SEM. ${ }^{*}$ Significant differences from the sex + saline/sex group $(p<0.05)$.

ous studies (Agmo and Berenfeld, 1990; Pfaus and Phillips, 1991; Tenk et al., 2009), mating in saline-pretreated control males resulted in $\mathrm{CPP}$-males spent more time in the sex + saline-paired chamber than the saline-paired chamber during the posttest $(p=$ 0.001 ; Fig. $6 C, D)$. In addition, control males did not form a preference for the sex + saline-paired chamber over the sex-paired chamber, demonstrating that a saline injection before mating did not affect sexual reward (Fig. 6C,D). Results showed that Meth increased CPP for sex compared with either mating or Meth alone. Males spent more time during the posttest in the sex + Meth-paired chamber than the sex-paired chamber $(p<0.001$; Fig. $6 C)$ or the Meth-paired chamber $(p=0.02$; Fig. $6 C)$, or compared with the control group ( $p=0.002$ and 0.05 , respectively; Fig. $6 D$ ). Therefore, sexual behavior concurrent with Meth appears to be more rewarding than sexual behavior or Meth alone in animals that were pretreated with sexual behavior and Meth concurrently.

\section{Experiment 2}

Next, it was determined whether concurrent pretreatment of Meth and sex influenced CPP for Meth alone compared with saline treatment in the unpaired chamber. Indeed, Methpretreated males that mated concurrently with each drug injection formed a preference for the Meth-paired chamber $(p=0.01$; Fig. 7). In contrast, males that received repeated saline or Meth injections without the context of mating did not show increased preference for the Meth-paired chamber during the posttest.

\section{Experiment 3}

Finally, it was tested whether concurrent Meth and mating pretreatment affected CPP for mating alone. Males pretreated with Meth and mating did not form a preference for sexual behavior, evidenced by a lack of increased time spent in the sex-paired chamber. In contrast, males that were treated with saline and mating did form a preference for the sex-paired chamber $(p=0.003$; Fig. 8$)$. Together, these data suggest that the association between Meth and mating results in increased incentive salience for Meth in the absence of mating and for mating concurrently with Meth, but reduced incentive salience for mating in the absence of the drug.

\section{Discussion}

The current study tested the effects of repeated Meth on sexual behavior with specific focus on sexual performance, maladaptive or compulsive sex-seeking, and mating and/or Meth reward. The main finding of this study was that Meth pretreatment did not affect expression of sexual behavior, but caused compulsive sexual behavior in the weeks following pretreatment. This effect on compulsive sexual behavior was dependent on the concurrent experience with Meth and mating. Furthermore, concurrent Meth and mating pretreatments enhanced Meth reward, but reduced sexual reward. Together, these studies show that an association between Meth and mating is critical for the development or expression of compulsive sexual behavior and changes in sexual and drug reward. 


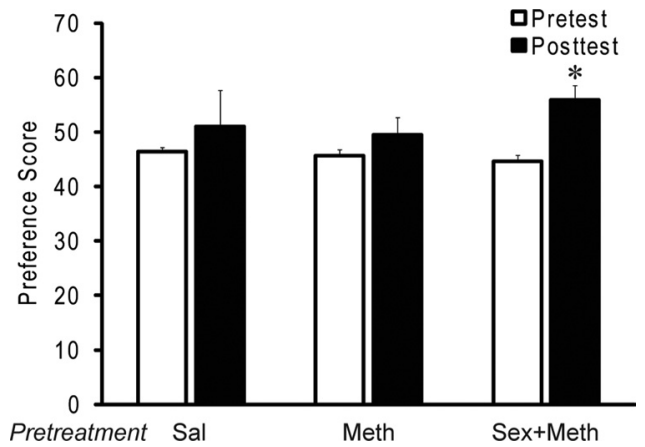

Figure 7. Effects of concurrent mating (sex) and Meth pretreatment on Meth-induced CPP (Experiment 2). Preference score (time spent on paired chamber divided by time in paired + unpaired chamber $\times 100$ ) in males pretreated with saline (Sal), Meth, or sex + Meth. Data are presented as mean \pm SEM. ${ }^{*}$ Significant difference from pretest within the same experimental group $(p<0.05)$.

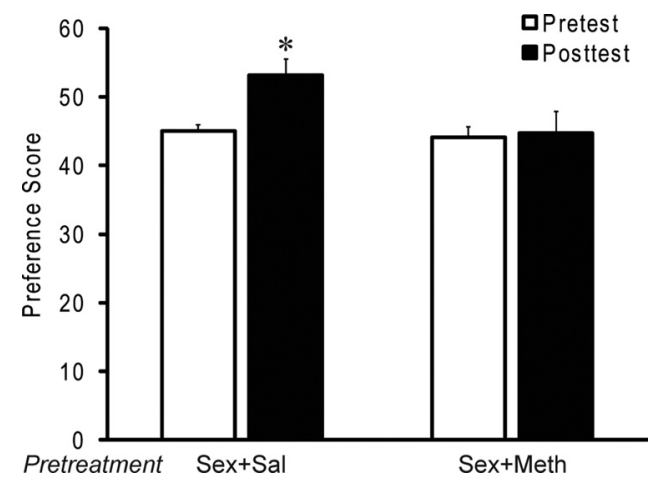

Figure 8. Effects of concurrent mating (sex) and Meth pretreatment on mating-induced CPP (Experiment3). Preferencescore (timespent on paired chamber divided by time in paired + unpaired chamber $\times 100$ ) in males pretreated with sex + saline $(S a l)$ or sex + Meth. Data are presented as mean \pm SEM

Meth pretreatment, when concurrent with mating, had long-term effects on the ability of the conditioned sex aversion paradigm to inhibit sexual behavior. This effect cannot readily be explained by a deficit in learning or memory, since Meth-pretreated males did not show any evidence of impaired learning during CPP or LiCl-induced sex aversion paradigms. In addition, it is unlikely that repeated administration of the low dose of Meth caused the cognitive impairments and neurotoxicity typically seen following chronic exposure to high doses of Meth in rats (Walsh and Wagner, 1992; Friedman et al., 1998; Chapman et al., 2001; Schröder et al., 2003) and humans (Ornstein et al., 2000; Simon et al., 2002; Kalechstein et al., 2003), as single-day Meth bingeing paradigms using the same dose as the current study did not impair objectrecognition learning and did not result in neurotoxicity (Marshall et al., 2007). Another alternate explanation for the impaired acquisition or expression of conditioned sex aversion is a loss of sensitivity for $\mathrm{LiCl}$. However, animals were equally capable of acquire a conditioned aversion to a chamber previously paired with $\mathrm{LiCl}$. Hence, Meth-pretreated males did not have impaired associative memory or reduced sensitivity to $\mathrm{LiCl}$ or $\mathrm{LiCl}$-induced illness. It appears that Meth pretreatment caused maladaptive or compulsive sex seeking, despite learned negative consequences, which is in line with human reports (Frosch et al., 1996; Halkitis et al., 2001; McKirnan et al., 2001; Rawson et al., 2002; Somlai et al., 2003; Green and Halkitis, 2006; Springer et al., 2007).

Moreover, the effect of Meth and mating pretreatment on reduced inhibition of maladaptive sexual behavior is not readily explained by an enhanced reward associated with mating. In contrast, in animals that received concurrent Meth and mating experience, reward-seeking associated with mating was reduced. Therefore, another explanation must be proposed for the effects of concurrent Meth and mating pretreatment on the expression of maladaptive sexual behavior. A recent neuroanatomical study from our laboratory identified brain areas where Meth may mediate effects on sexual behavior (Frohmader et al., 2010c). Here, neural activation induced by mating or Meth was examined using neural activity markers such as Fos or phosphorylation of MAPK, respectively. Meth and mating coactivated neurons in the nucleus accumbens, basolateral amygdala, and the anterior cingulate area of the medial prefrontal cortex (Frohmader et al., 2010c) and in the orbitofrontal cortex (Frohmader and Coolen, 2010). The prefrontal and orbitofrontal cortices are of particular interest as they contribute to addictive behaviors (Kalivas and Volkow, 2005; Kalivas et al., 2005; Lasseter et al., 2010; Winstanley et al., 2010). Moreover, hypoactivity of these brain areas has been correlated with several psychiatric conditions associated with loss of inhibitory control (Graybiel and Rauch, 2000; Taylor et al., 2002; London et al., 2005). These lines of evidence suggest that Meth may act in these frontal cortices to cause long-term alterations that in turn mediate compulsive sexual behavior. In line with this, high incidence of compulsive sexual behavior has been shown to overlap with other psychiatric disorders, including drug addiction, anxiety, and mood disorders (Bancroft, 2008). Also, drug-induced dysfunction of the medial prefrontal and orbitofrontal cortices are hypothesized to be responsible for reduced impulse control (Brewer and Potenza, 2008; Fineberg et al., 2010) and increased sex-directed behavior observed in many addicts (Jentsch and Taylor, 1999; Bancroft, 2008). In agreement with this, lesions of the medial prefrontal cortex in male rats resulted in compulsive sex-seeking behavior in the conditioned sex aversion paradigm used in the current studies (Davis et al., 2010).

Previous research has shown that repeated administration to psychostimulants or opiates enhances drug-induced reward as measured by CPP (Lett, 1989; Shippenberg and Heidbreder, 1995; Shippenberg et al., 1996). In addition, sexual experience caused subsequent sensitization of D-amphetamine reward (Pitchers et al., 2010). In the current study, the effects of Meth and/or sexual experience on Meth CPP was tested under conditions that were not expected to result in drug CPP: low dose of Meth, a single conditioning trial, and testing during the dark phase of the day at times of lowest CPP (Webb et al., 2009a,b). The sensitizing regimens of repeated Meth or of sexual experience used in the current study did not cause enhanced Meth CPP. However, Meth pretreatment concurrent with mating did enhance Meth reward, indicating that this association between Meth and mating caused an enhancement in reward seeking for Meth. These results appear in agreement with human reports of increased Meth seeking indentifying sexual pleasure during Meth taking as a primary drive for drug use (Semple et al., 2002; Schilder et al., 2005; Green and Halkitis, 2006). It is currently unclear which components of sexual behavior are critical for the association between Meth and mating. In the current study, all males mated to ejaculation. However, our previous findings suggest that social interactions may be sufficient to induce maladaptive sex-seeking behavior (Frohmader et al., 2010a).

Neural substrates that may mediate the enhancing effects of concurrent Meth and mating pretreatment on Meth reward include the nucleus accumbens and basolateral amygdala. Longlasting changes in dendritic spine density and morphology in the accumbens result from repeated drug administration (Brown and Kolb, 2001; Robinson et al., 2002; Li et al., 2003; Robinson 
and Kolb, 2004) or sexual experience (Meisel and Mullins, 2006; Pitchers et al., 2010), and are hypothesized to mediate druginduced locomotor and reward sensitization (Pierce and Kalivas, 1997; Vanderschuren and Kalivas, 2000; Li et al., 2004). The basolateral amygdala is critical for memory of conditioned stimuli associated with drug stimuli (Grace and Rosenkranz, 2002; Laviolette and Grace, 2006) and involved in reward sensitization and reinforcement (Everitt et al., 1999; Cardinal et al., 2002; See, 2002). Lesions or inactivations of the basolateral amygdala block the acquisition (Whitelaw et al., 1996) and expression (Grimm and See, 2000) of conditioned-cued cocaine reinstatement. Moreover, basolateral amygdala lesions result in reduced responding for conditioned stimuli paired with food (Everitt et al., 1989) or sexual reinforcement (Everitt et al., 1989; Everitt, 1990) in rats. Therefore, it is possible that psychostimulant- and mating-induced changes in accumbens and basolateral amygdala result in potentiated reward salience of Meth.

Sensitizing regiments of drugs have been shown to facilitate sexual behavior. Sensitizing pretreatments of D-amphetamine (10 daily injections of $1.5 \mathrm{mg} / \mathrm{kg}$ ) facilitate sexual behavior (Fiorino and Phillips, 1999a,b) as well as approach behavior to sexual stimuli (Nocjar and Panksepp, 2002). Studies in female rats pretreated with Meth (three daily injections of $5 \mathrm{mg} / \mathrm{kg}$ ) resulted in increased receptive behaviors (Holder et al., 2010). In contrast, the current study did not show effects of a sensitizing regiment of Meth treatment on sexual behavior. Possible explanations for this discrepancy include the lower drug dosing used in the current study, different assessments of sexual motivation, and sex differences (Becker and $\mathrm{Hu}, 2008$ ).

Studies on rodent models of Meth addiction have recently focused on drug bingeing paradigms to investigate Meth-induced behavioral impairments (Belcher et al., 2008; Izquierdo et al., 2010; O'Dell et al., 2011), neuroplastic changes (Brennan et al., 2010), and neurotoxicity (Moszczynska et al., 1998; Kuczenski et al., 2007; Graham et al., 2008). The main objective of these studies was to achieve plasma drug levels in the rat close to those found in human Meth addicts. In contrast, the current study demonstrated that once daily passive administration of low-dose Meth was sufficient to cause long-lasting compulsive sexual behavior. A Meth bingeing paradigm was not used for practical reasons: high doses of Meth impair sexual behavior (Frohmader et al., 2010a) and human users often use sexual performance enhancing drugs to maintain sexual function (Semple et al., 2009). The focus of the current sets of studies was to investigate sexual reward and compulsive mating in animals with unimpaired mating behavior. The results demonstrate that compulsive sexual behavior and altered drug and sexual reward can be caused by very low drug exposure once concurrent with sexual experience and are not dependent on inducing bingeing levels of Meth in the brain.

Together, the current set of studies form an important step toward a better understanding of the effects of Meth on compulsive sexual behavior and associations between drug and sexual reward. Moreover, these data parallel those reported in human addicts; thus, the male rat model can be further used to examine molecular and structural mechanisms of Meth effects on sexual behavior and potentially contribute to future drug addiction therapies.

\section{References}

Agmo A (2002) Copulation-contingent aversive conditioning and sexual incentive motivation in male rats: evidence for a two-stage process of sexual behavior. Physiol Behav 77:425-435.

Agmo A, Berenfeld R (1990) Reinforcing properties of ejaculation in the male rat: role of opioids and dopamine. Behav Neurosci 104:177-182.
Bancroft J (2008) Sexual behavior that is "out of control": a theoretical conceptual approach. Psychiatr Clin North Am 31:593-601.

Becker JB, Hu M (2008) Sex differences in drug abuse. Front Neuroendocrinol 29:36-47.

Belcher AM, Feinstein EM, O'Dell SJ, Marshall JF (2008) Methamphetamine influences on recognition memory: comparison of escalating and single-day dosing regimens. Neuropsychopharmacology 33:1453-1463.

Brennan KA, Colussi-Mas J, Carati C, Lea RA, Fitzmaurice PS, Schenk S (2010) Methamphetamine self-administration and the effect of contingency on monoamine and metabolite tissue levels in the rat. Brain Res 1317:137-146.

Brewer JA, Potenza MN (2008) The neurobiology and genetics of impulse control disorders: relationships to drug addictions. Biochem Pharmacol 75:63-75.

Brown RW, Kolb B (2001) Nicotine sensitization increases dendritic length and spine density in the nucleus accumbens and cingulate cortex. Brain Res 899:94-100.

Cardinal RN, Parkinson JA, Hall J, Everitt BJ (2002) Emotion and motivation: the role of the amygdala, ventral striatum, and prefrontal cortex. Neurosci Biobehav Rev 26:321-352.

Chapman DE, Hanson GR, Kesner RP, Keefe KA (2001) Long-term changes in basal ganglia function after a neurotoxic regimen of methamphetamine. J Pharmacol Exp Ther 296:520-527.

Crowe LC, George WH (1989) Alcohol and human sexuality: review and integration. Psychol Bull 105:374-386.

Davis JF, Loos M, Di Sebastiano AR, Brown JL, Lehman MN, Coolen LM (2010) Lesions of the medial prefrontal cortex cause maladaptive sexual behavior in male rats. Biol Psychiatry 67:1199-1204.

Everitt BJ (1990) Sexual motivation: a neural and behavioural analysis of the mechanisms underlying appetitive and copulatory responses of male rats. Neurosci Biobehav Rev 14:217-232.

Everitt BJ, Cador M, Robbins TW (1989) Interactions between the amygdala and ventral striatum in stimulus-reward associations: studies using a second-order schedule of sexual reinforcement. Neuroscience 30:63-75.

Everitt BJ, Parkinson JA, Olmstead MC, Arroyo M, Robledo P, Robbins TW (1999) Associative processes in addiction and reward the role of amygdala-ventral striatal subsystems. Ann N Y Acad Sci 877:412-438.

Fineberg NA, Potenza MN, Chamberlain SR, Berlin HA, Menzies L, Bechara A, Sahakian BJ, Robbins TW, Bullmore ET, Hollander E (2010) Probing compulsive and impulsive behaviors, from animal models to endophenotypes: a narrative review. Neuropsychopharmacology 35:591-604.

Fiorino DF, Phillips AG (1999a) Facilitation of sexual behavior in male rats following d-amphetamine-induced behavioral sensitization. Psychopharmacology 142:200-208.

Fiorino DF, Phillips AG (1999b) Facilitation of sexual behavior and enhanced dopamine efflux in the nucleus accumbens of male rats after D-amphetamine-induced behavioral sensitization. J Neurosci 19:456-463.

Fisher DG, Reynolds GL, Ware MR, Napper LE (2011) Methamphetamine and viagra use: relationship to sexual risk behaviors. Arch Sex Behav 40:273-279.

Friedman SD, Castañeda E, Hodge GK (1998) Long-term monoamine depletion, differential recovery, and subtle behavioral impairment following methamphetamine-induced neurotoxicity. Pharmacol Biochem Behav 61:35-44.

Frohmader KS, Coolen LM (2010) Effects of methamphetamine on maladaptive sexual behavior and underlying neural substrates. Soc Neurosci Abstr 36:595.18.

Frohmader KS, Bateman KL, Lehman MN, Coolen LM (2010a) Effects of methamphetamine on sexual performance and compulsive sex behavior in male rats. Psychopharmacology (Berl) 212:93-104.

Frohmader KS, Pitchers KK, Balfour ME, Coolen LM (2010b) Mixing pleasures: review of the effects of drugs on sex behavior in humans and animal models. Horm Behav 58:149-162.

Frohmader KS, Wiskerke J, Wise RA, Lehman MN, Coolen LM (2010c) Methamphetamine acts on subpopulations of neurons regulating sexual behavior in male rats. Neuroscience 166:771-784.

Frosch D, Shoptaw S, Huber A, Rawson RA, Ling W (1996) Sexual HIV risk among gay and bisexual male methamphetamine abusers. J Subst Abuse Treat 13:483-486.

Grace AA, Rosenkranz JA (2002) Regulation of conditioned responses of basolateral amygdala neurons. Physiol Behav 77:489-493. 
Graham DL, Noailles PA, Cadet JL (2008) Differential neurochemical consequences of an escalating dose-binge regimen followed by single-day multipledose methamphetamine challenges. J Neurochem 105:1873-1885.

Graybiel AM, Rauch SL (2000) Toward a neurobiology of obsessivecompulsive disorder. Neuron 28:343-347.

Green AI, Halkitis PN (2006) Crystal methamphetamine and sexual sociality in an urban gay subculture: an elective affinity. Cult Health Sex 8:317-333.

Grimm JW, See RE (2000) Dissociation of primary and secondary rewardrelevant limbic nuclei in an animal model of relapse. Neuropsychopharmacology 22:473-479.

Halkitis PN, Parsons JT, Stirratt MJ (2001) A double epidemic: crystal methamphetamine drug use in relation to HIV transmission among gay men. J Homosex 41:17-35.

Holder MK, Hadjimarkou MM, Zup SL, Blutstein T, Benham RS, McCarthy MM, Mong JA (2010) Methamphetamine facilitates female sexual behavior and enhances neuronal activation in the medial amygdala and ventromedial nucleus of the hypothalamus. Psychoneuroendocrinology $35: 197-208$

Hull EM, Meisel RL, Sachs BD (2002) Male sexual behavior. In: Hormones brain and behavior (Pfaff DW, Arnold AP, Etgen AM, Fahrbach SE, Rubin RT, eds), pp 1-138. San Diego: Elsevier Science.

Izquierdo A, Belcher AM, Scott L, Cazares VA, Chen J, O’Dell SJ, Malvaez M, Wu T, Marshall JF (2010) Reversal-specific learning impairments after a binge regimen of methamphetamine in rats: possible involvement of striatal dopamine. Neuropsychopharmacology 35:505-514.

Jentsch JD, Taylor JR (1999) Impulsivity resulting from frontostriatal dysfunction in drug abuse: implications for the control of behavior by reward-related stimuli. Psychopharmacology (Berl) 146:373-390.

Kalechstein AD, Newton TF, Green M (2003) Methamphetamine dependence is associated with neurocognitive impairment in the initial phases of abstinence. J Neuropsychiatry Clin Neurosci 15:215-220.

Kalivas PW, Volkow ND (2005) The neural basis of addiction: a pathology of motivation and choice. Am J Psychiatry 162:1403-1413.

Kalivas PW, Volkow N, Seamans J (2005) Unmanageable motivation in addiction: a pathology in prefrontal-accumbens glutamate transmission. Neuron 45:647-650.

Kuczenski R, Everall IP, Crews L, Adame A, Grant I, Masliah E (2007) Escalating dose-multiple binge methamphetamine exposure results in degeneration of the neocortex and limbic system in the rat. Exp Neurol 207:42-51.

Lasseter HC, Xie X, Ramirez DR, Fuchs RA (2010) Prefrontal cortical regulation of drug seeking in animal models of drug relapse. In: Behavioral neuroscience of drug addiction (Self DW, Staley Gottschalk JK, eds), pp 101-117. Berlin: Springer.

Laviolette SR, Grace AA (2006) Cannabinoids potentiate emotional learning plasticity in neurons of the medial prefrontal cortex through basolateral amygdala inputs. J Neurosci 26:6458-6468.

Lawrence GJ, Kiefer SW (1987) Cessation of male rat copulatory behavior using illness as punishment: facilitation with a novel odor. Behav Neurosci 101:289-291.

Lett BT (1989) Repeated exposures intensify rather than diminish the rewarding effects of amphetamine, morphine, and cocaine. Psychopharmacology (Berl) 98:357-362.

Li Y, Kolb B, Robinson TE (2003) The location of persistent amphetamineinduced changes in the density of dendritic spines on medium spiny neurons in the nucleus accumbens and caudate-putamen. Neuropsychopharmacology 28:1082-1085.

Li Y, Acerbo MJ, Robinson TE (2004) The induction of behavioural sensitization is associated with cocaine-induced structural plasticity in the core (but not shell) of the nucleus accumbens. Eur J Neurosci 20:1647-1654.

London ED, Berman SM, Voytek B, Simon SL, Mandelkern MA, Monterosso J, Thompson PM, Brody AL, Geaga JA, Hong MS, Hayashi KM, Rawson RA, Ling W (2005) Cerebral metabolic dysfunction and impaired vigilance in recently abstinent methamphetamine abusers. Biol Psychiatry 58:770-778.

Marshall JF, Belcher AM, Feinstein EM, O’Dell SJ (2007) Methamphetamineinduced neural and cognitive changes in rodents. Addiction 102:61-69.

McKirnan DJ, Vanable PA, Ostrow DG, Hope B (2001) Expectancies of sexual "escape" and sexual risk among drug and alcohol-involved gay and bisexual men. J Subst Abuse 13:137-154.

Meisel RL, Mullins AJ (2006) Sexual experience in female rodents: cellular mechanisms and functional consequences. Brain Res 1126:56-65.
Moszczynska A, Turenne S, Kish SJ (1998) Rat striatal levels of the antioxidant glutathione are decreased following binge administration of methamphetamine. Neurosci Lett 255:49-52.

Nocjar C, Panksepp J (2002) Chronic intermittent amphetamine pretreatment enhances future appetitive behavior for drug- and natural-reward: interaction with environmental variables. Behav Brain Res 128:189-203.

O'Dell SJ, Feinberg LM, Marshall JF (2011) A neurotoxic regimen of methamphetamine impairs novelty recognition as measured by a social odorbased task. Behav Brain Res 216:396-401.

Ornstein TJ, Iddon JL, Baldacchino AM, Sahakian BJ, London M, Everitt BJ, Robbins TW (2000) Profiles of cognitive dysfunction in chronic amphetamine and heroin abusers. Neuropsychopharmacology 23:113-126.

Parsons JT, Halkitis PN (2002) Sexual and drug-using practices of HIVpositive men who frequent public and commercial sex environments. AIDS Care 14:815-826.

Peters RH (1983) Learned aversions to copulatory behaviors in male rats. Behav Neurosci 97:140-145.

Peugh J, Belenko S (2001) Alcohol, drugs and sexual function: a review. J Psychoactive Drugs 33:223-232.

Pfaus JG (2009) Pathways of sexual desire. J Sex Med 6:1506-1533.

Pfaus JG, Phillips AG (1991) Role of dopamine in anticipatory and consummatory aspects of sexual behavior in the male rat. Behav Neurosci 105:727-743.

Pierce RC, Kalivas PW (1997) A circuitry model of the expression of behavioral sensitization to amphetamine-like psychostimulants. Brain Res Rev 25:192-216.

Pitchers KK, Balfour ME, Lehman MN, Richtand NM, Yu L, Coolen LM (2010) Neuroplasticity in the mesolimbic system induced by natural reward and subsequent reward abstinence. Biol Psychiatry 67:872-879.

Raj A, Saitz R, Cheng DM, Winter M, Samet JH (2007) Associations between alcohol, heroin, and cocaine use and high risk sexual behaviors among detoxification patients. Am J Drug Alcohol Abuse 33:169-178.

Rawson RA, Washton A, Domier CP, Reiber C (2002) Drugs and sexual effects: role of drug type and gender. J Subst Abuse Treat 22:103-108.

Robinson TE, Kolb B (2004) Structural plasticity associated with exposure to drugs of abuse. Neuropharmacology 47 [Suppl 1]:33-46.

Robinson TE, Gorny G, Savage VR, Kolb B (2002) Widespread but regionally specific effects of experimenter- versus self-administered morphine on dendritic spines in the nucleus accumbens, hippocampus, and neocortex of adult rats. Synapse 46:271-279.

Sánchez J, Comerford M, Chitwood DD, Fernandez MI, McCoy CB (2002) High risk sexual behaviours among heroin sniffers who have no history of injection drug use: implications for HIV risk reduction. AIDS Care 14:391-398.

Schilder AJ, Lampinen TM, Miller ML, Hogg RS (2005) Crystal methamphetamine and ecstasy differ in relation to unsafe sex among young gay men. Can J Public Health 96:340-343.

Schröder N, O'Dell SJ, Marshall JF (2003) Neurotoxic methamphetamine regimen severely impairs recognition memory in rats. Synapse 49:89-96.

See RE (2002) Neural substrates of conditioned-cued relapse to drugseeking behavior. Pharmacol Biochem Behav 71:517-529.

Semple SJ, Patterson TL, Grant I (2002) Motivations associated with methamphetamine use among HIV men who have sex with men. J Subst Abuse Treat 22:149-156.

Semple SJ, Strathdee SA, Zians J, Patterson TL (2009) Sexual risk behavior associated with co-administration of methamphetamine and other drugs in a sample of HIV-positive men who have sex with men. Am J Addict 18:65-72.

Shippenberg TS, Heidbreder C (1995) Sensitization to the conditioned rewarding effects of cocaine: pharmacological and temporal characteristics. J Pharmacol Exp Ther 273:808-815.

Shippenberg TS, Heidbreder C, Lefevour A (1996) Sensitization to the conditioned rewarding effects of morphine: pharmacology and temporal characteristics. Eur J Pharmacol 299:33-39.

Simon SL, Domier CP, Sim T, Richardson K, Rawson RA, Ling W (2002) Cognitive performance of current methamphetamine and cocaine abusers. J Addict Dis 21:61-74.

Somlai AM, Kelly JA, McAuliffe TL, Ksobiech K, Hackl KL (2003) Predictors of HIV sexual risk behaviors in a community sample of injection drug-using men and women. AIDS Behav 7:383-393. 
Springer AE, Peters RJ, Shegog R, White DL, Kelder SH (2007) Methamphetamine use and sexual risk behaviors in U.S. high school students: findings from a national risk behavior survey. Prev Sci 8:103-113.

Taylor SF, Liberzon I, Decker LR, Koeppe RA (2002) A functional anatomic study of emotion in schizophrenia. Schizophr Res 58:159-172.

Tenk CM, Wilson H, Zhang Q, Pitchers KK, Coolen LM (2009) Sexual reward in male rats: effects of sexual experience on conditioned place preferences associated with ejaculation and intromissions. Horm Behav 55:93-97.

Vanderschuren LJ, Kalivas PW (2000) Alterations in dopaminergic and glutamatergic transmission in the induction and expression of behavioral sensitization: a critical review of preclinical studies. Psychopharmacology (Berl) 151:99-120.

Walsh SL, Wagner GC (1992) Motor impairments after methamphetamineinduced neurotoxicity in the rat. J Pharmacol Exp Ther 263:617-626.
Webb IC, Baltazar RM, Lehman MN, Coolen LM (2009a) Bidirectional interactions between the circadian and reward systems: is restricted food access a unique zeitgeber? Eur J Neurosci 30:1739-1748.

Webb IC, Baltazar RM, Wang X, Pitchers KK, Coolen LM, Lehman MN (2009b) Diurnal variations in natural and drug reward, mesolimbic tyrosine hydroxylase, and clock gene expression in the male rat. J Biol Rhythms 24:465-476.

Whitelaw RB, Markou A, Robbins TW, Everitt BJ (1996) Excitotoxic lesions of the basolateral amygdala impair the acquisition of cocaine-seeking behaviour under a second-order schedule of reinforcement. Psychopharmacology 127:213-224

Winstanley CA, Olausson P, Taylor JR, Jentsch JD (2010) Insight into the relationship between impulsivity and substance abuse from studies using animal models. Alcohol Clin Exp Res 34:1306-1318. 